\title{
Conference wet lab: is an IACUC needed?
}

For many years the Eastern Veterinary Conference took place in a convention center located about 5 miles from the veterinary school of Great Eastern University. One of the most popular features of the conference was a wet lab on small ruminant (e.g., sheep, goats) anesthesia and analgesia. The lab, which was held on the premises of the University, focused on the training needs of private-practice veterinary technicians, although some Great Eastern research and veterinary technicians periodically attended. The school acted as a sponsor and overseer of the training lab, and the Great Eastern IACUC routinely reviewed and approved the training activity.

SOCRATES (Students Opposed to Cruel Animal Testing) was a campus group opposed to research and teaching using live animals. It was also opposed to the wet labs. Originally viewed as little more than a nuisance to the veterinary school, over the years the group continued to petition and demonstrate to stop the wet labs. Eventually, the University administration decided that its time could be better spent on other matters and told the conference organizers to hold the labs elsewhere. This was not easy to do because there were no other animal-using institutions available. In desperation, the organizers decided to hold the wet lab within the convention center. "Why not?" said Bill Henry, the conference's chairman, "There are live animal demonstrations and teaching at fairs, circuses, and other meetings. We can do the same thing."

"And do they need IACUCs for these demonstrations?" asked Anne Goode, a member of the organizing committee?

"I don't know" Henry responded, "but I can find out. My guess is that none of them have IACUCs, because none of them use research animals. We're pretty much in the same boat, just teaching folks how to work with small ruminants."

"OK," said Goode, "but I'll bet we do need an IACUC, and if we do, I can envision all kinds of problems getting this plan to work. Let me know what you find out and we'll take it from there."

Does the Eastern Veterinary Conference even need an IACUC and IACUC approval to hold its live animal wet lab at the convention center? If it does, what are the critical hurdles to implementation that face Henry and his committee? How might they overcome them?

\section{RESPONSE}

\section{Agriculture exemption}

\section{Nirah H Shomer, DVM, PhD, DACLAM}

There are three types of institutions that require an IACUC:

1. Institutions receiving Public Health Service (PHS) funds because PHS Policy on Humane Care and Use of Laboratory Animals (PHS Policy) requires adherence to the Guide for Care and Use of Laboratory Animals (Guide) and the Guide for Care and Use of Agricultural Animals in Agricultural Research and Teaching (Ag Guide), and both of these documents mandate an IACUC.

2. Institutions accredited by the Association for Assessment and Accreditation of Laboratory Animal Care International (because AAALAC generally uses the Guide as a basis of accreditation for institutions based in the United States).

3. Institutions that require an IACUC under the Animal Welfare Regulations (AWA).

The first two institutional types are evi- dently not applicable, although the Eastern Veterinary Conference should carefully scrutinize their funding sources to ensure they are not receiving funds from any agency of the PHS. However, the AWA does need to be considered here. In researching this answer, I used the document "Licensing and Registration Under the Animal Welfare Act-Guidelines for Dealers, Exhibitors, Transporters, and Researchers ${ }^{1}$."

The AWA covers a variety of activities with animals. The regulations may mandate licensing or registration, but an IACUC is a requirement only for institutions using animals in research, teaching, or testing. The United States Department of Agriculture (USDA) recognizes four major areas of activity: dealer, transporter, exhibitor, and researcher. The Eastern Veterinary Conference would not have the status of a 'dealer', unless it plans to sell the animals or give them away as prizes after the demonstration. The conference would not have the status of an animal 'transporter', although they should take care that the carrier they use is properly licensed. The wet lab is arguably an 'exhibition'. There is an exemption for farm animal exhibits, but this exemption does not apply if the animals are not being used for agricultural purposes; thus I believe this exemption does not apply because it is a hands-on teaching lab. Therefore, it appears that the organizers must obtain an exhibitor's license for the wet lab. The wet lab does not have a fixed, yearround location, so it would have to follow the rules for a traveling animal show and provide an itinerary that would allow the USDA to inspect it on location.

Finally, the really relevant question is whether this usage would fall under the regulations for research, teaching, and testing. Although these animals are used for teaching, the regulations exempt agricultural research institutions. The guidelines state that " $[r]$ esearch institutions that perform work involving food, fiber, or agriculture and that use horses and domestic farm animals, including rabbits, are exempt by regulation and do not have to be registered ${ }^{1}$."

Does this wet lab meet the criteria for exemption? For further clarification, USDA Policy \#26 (ref. 2) states that: "Farm animals, such as domestic cattle, horses, sheep, swine, and goats that are used for traditional, pro- 